\title{
The control of chiasma formation in colchicine treated meiocytes of Senecio squalidus
}

\author{
Andrew M. Thomson and \\ Ruth Ingram
}

Department of Plant Biology and Ecology, University of St. Andrews, St. Andrews, Fife.

\begin{abstract}
Colchicine induced multivalent formation is used to examine the effects of multivalent formation on chiasma frequency in Senecio squalidus. The increases observed are interpreted as the results of increases in numbers of pairing segments or decreases of chiasma interference following pairing partner exchange.
\end{abstract}

\section{INTRODUCTION}

Several studies have indicated that colchicine has the effect of disrupting normal pairing in meiocytes. Driscoll et al. (1967) first used the method to show disruption of normal bivalent pairing in wheat, with consequent multivalent formation which appeared to express the genomic homeology which is normally under the control of chromosome 5B. More recently, Murray et al. (1983) have used a similar method in Helianthus annuus which is normally considered to be a diploid species, and again multivalents were produced though normal bivalent pairing was disrupted to a lower extent. They interpreted this to mean that ancient genome homologies were being revealed and that the species was an ancient polyploid.

Whatever the evolutionary implications of such results may be, the method can be used to study chiasma formation in relation to pairing within the genome.

Parker et al (1982) demonstrated clearly that interchange heterozygosity induced increased chiasma frequency equivalent to the increased number of discrete pairing segments in the genome in the quadrivalent produced by the interchange. A similar effect due to inversion heterozygosity had been previously reported by Maguire (1977). In the present study, colchicine was used to induce multivalent formation in the buds of $S$. squalidus L. $(2 n=20)$, a species which is normally considered to be diploid, though there is some evidence that the base number of the genus may be 5 (Alexander, 1979 for review). However, the evolutionary implications are not the important aspects of this study.
The main interest lies in the effect which multivalent formation, and its coincident increase in discrete pairing segments, has on chiasma frequency.

\section{METHODS}

Stems of $S$. squalidus were cut under water and then immediately placed in colchicine solution $(0.05$ per cent $\mathrm{w} / \mathrm{v})$ for a minimum of 24 hours. It was found that longer exposures than this were required in glasshouse conditions in winter, and up to $68 \mathrm{hrs}$ were sometimes required to produce an affect. The method was first used by Murray et al. (1983) Buds were subsequently fixed in ethanol; chloroform and propionic acid in the proportions $6: 3: 2$. Squash preparations were stained in lactopropionic orcein.

Controls were buds taken from the same plants but were not treated with colchicine.

\section{RESULTS}

The effect of colchicine was to cause multivalent formation in some florets of the treated capitula. Not all florets were affected, and this reflects the normal developmental pattern of the capitulum in which only a few florets are likely to undergo meiosis in any period of 24 hours. Within the florets in which multivalent formation was apparent, there were many cells in which only bivalents formed. These cells showed no evidence of pairing failure, and there was therefore no means of telling whether they had been affected by the colchicine or whether colchicine had been ineffective due to minor developmental variations. 
Table 1

\begin{tabular}{|c|c|c|c|c|c|c|c|c|c|}
\hline \multirow[b]{2}{*}{ Plant } & \multirow[b]{2}{*}{ I } & \multirow[b]{2}{*}{ cII } & \multicolumn{3}{|c|}{ Configurations } & \multirow[b]{2}{*}{ oIV } & \multirow[b]{2}{*}{ Chiasmata } & \multirow{2}{*}{$\begin{array}{l}\text { No. of } \\
\text { cells }\end{array}$} & \multirow{2}{*}{$\begin{array}{l}\text { Chiasmata/cell } \\
\text { + confidence limits }\end{array}$} \\
\hline & & & oII & III & cIV & & & & \\
\hline 1 Control & 0 & 266 & 52 & 0 & 1 & 0 & 373 & 32 & $11 \cdot 66 \pm 0 \cdot 21$ \\
\hline Treated & 6 & 179 & 41 & 6 & 21 & 3 & 348 & 28 & $12.42 \pm 0.58$ \\
\hline 2 Control & 0 & 271 & 49 & 0 & 0 & 0 & 369 & 32 & $11 \cdot 25 \pm 0.25$ \\
\hline Treated & 4 & 186 & 45 & 2 & 24 & 3 & 364 & 29 & $12 \cdot 55 \pm 0 \cdot 33$ \\
\hline
\end{tabular}

In view of this uncertainty, only cells which showed multivalent formation are used in this analysis.

The pairing analysis of these selected cells is summarised in table 1.

Most of the cells showing multivalent formation showed 1 multivalent per cell (quadrivalent or trivalent plus univalent) and there was no evidence of any general pairing failure in the rest of the chromosome complement, though one or two cells showed the formation of one pair of univalents.

The major point of interest lies in the increased chiasma frequency in cells in which multivalents occur: i.e., the formation of multivalents is not compensated by any marked reduction in the number of ring bivalents or by regular desynapsis. Multivalents represent the occurrence of pairing partner switches at zygotene which are stabilised by chiasmata, and represent a minimal estimate of the number of such switches which actually occurred. However, in view of the low chiasma frequency of the control plants, it is remarkable that multivalents occurred without any apparent decrease in chiasmata in the rest of the genome, which would have lead to either a decrease in the number of ring bivalents per cell or the occurrence of univalents due to desynapsis.

The increased chiasma frequency which prevented either of these events can be explained in several ways. Maguire (1977) and Parker et al. (1982) both link chiasma formation with the initiation of pairing in discrete pairing segments of chromosomes. The results reported here can be interpreted in the same way if we postulate that switches in pairing partner at zygotene have resulted in an increased number of discrete pairing segments. Thus a chain quadrivalent would represent an increase of one pairing segment over two bivalents. A trivalent + univalent, however, would not represent any such increase. Another possibility is that pairing partner switches break the continuity of chiasma interference and allow extra chiasmata to form. Jones (1984) point out that it is very difficult to distinguish between the effects of new pairing segment initiation and the disrup- tion of chiasma interference. Certainly these effects cannot be separated in this investigation.

Although the methods used in this investigation were those of Murray et al. (1983), the investigations are not directly comparable. Murray et al. were investigating evolutionary aspects of the genomes of Helianthus, Alopecurus and Briza. In these taxa, as in Senecio, multivalents were formed in diploid species with very little general disruption of normal bivalent pairing in the rest of the genome. Mean chiasma frequency was not apparently altered in the population of cells analysed. However, the results show that many cells containing only bivalents must have been included in the analysis, and this would, of course, mask any increase occurring only in cells with multivalents. Another factor in Alopecurus and Briza is that both these taxa have a relatively high chiasma frequency and which may not be susceptible to further increase.

We do not wish to draw any conclusions regarding the origin of the Senecio genome from the work described in this paper. We feel that the multivalents recorded could be formed from duplicated parts of the genome and do not necessarily indicate ancient polyploidy.

\section{REFERENCES}

ALEXANDER, J. C. M. 1979. The Mediterranean species of Senecio and Delphinifolius. Notes Roy. Bot. Gard. Edin., 37, 387-430.

DRISCOLL, C. J., DARVEY, N. L. AND BARBER, H. N. 1967. Effect of colchicine on meiosis of hexaploid wheat. Nature, 216 , 687-688.

JONES, G. H. 1984. The control of chiasma distribution. Evans, C. W. and Dickinson, H. G. (eds.) In Controlling events in meiosis, S.E.B. Symp. no. XXXVIII, Cambridge pp. 293320.

maguire, M. P. 1977. Homologous chromosome pairing. Phil. Trans. Roy. Soc. Lond. Ser. B., 277, 245-258.

MURRAY, B. G., JACKSON, R. C. AND BARKER, N. R. N. 1983. Cryptic genome homologies revealed by premeiotic colchicine treatment of meiocytes. Brandham, P. E. and Bennett, M. D. (eds) Kew Chromosome Conference 11, Allen \& Unwin. London, pp. 165-171.

PARKER, J. S., PALMER, R. W., WHITEHORN, M. A. F. AND EDGAR, L. A, 1982. Chiasma frequency effects of structural chromosome change. Chromosoma, 85, 673-658. 